RESEARCH PAPER

\title{
Psychosocial work conditions, social capital, and daily smoking: a population based study
}

\section{$M$ Lindström}

See end of article for authors' affiliations ..................

Correspondence to: Dr Martin Lindström, Department of Community Medicine, Malmö

University Hospital, Lund University, S-205 02

Malmö, Sweden; martin.

lindstrom@smi.mas.lu.se

Received 8December 2003 Accepted 14 April 2004
Objective: To investigate the associations between psychosocial conditions at work, social capital/social participation, and daily smoking.

Design/setting/participants/measurements: The 2000 public health survey in Scania is a cross sectional postal questionnaire study with a $59 \%$ participation rate. A total of 5180 persons aged 18-64 years that belonged to the work force and the unemployed were included in this study. Logistic regression models were used to investigate the associations between psychosocial factors at work/unemployment, social participation, and daily smoking. Psychosocial conditions at work were defined according to the KarasekTheorell demand-control/decision latitudes into relaxed, active, passive, and jobstrain categories. The multivariate analyses included age, country of origin, education and economic stress.

Results: $17.2 \%$ proportion of all men and $21.9 \%$ of all women were daily smokers. The jobstrain (high demands/low control) and unemployed categories had significantly higher odds ratios of daily smoking among both men and women compared to the relaxed (low demands/high control) reference category. The passive (low demands/low control), jobstrain, and unemployed categories were also significantly associated with low social participation. Low social participation was significantly and positively associated with daily smoking within each of the psychosocial work conditions and unemployed categories.

Conclusions: The positive association between low social capital/low social participation and daily smoking is well known. However, both social participation and daily smoking are associated with psychosocial work conditions and unemployment. Psychosocial work conditions and unemployment may affect daily smoking both directly and through a pathway including social participation.
S ocial capital has been shown to affect public health through a number of causal pathways, including direct psychosocial mechanisms, norms and attitudes guiding health related behaviours, access to health care services and amenities, as well as crime, violence, and sense of security. ${ }^{12}$ A significant negative association between social capital (measured as either social participation or trust) and daily smoking has been documented. ${ }^{3}{ }^{4}$ A strong and significant positive association between social capital measured as social participation and smoking cessation among daily smokers has also been demonstrated. ${ }^{56}$

It is often argued that social capital and aspects of social capital such as social participation/social networks and trust are best promoted by stable social conditions such as stable social structures and low migration rates. Too much social turbulence weakens social ties and social networks. ${ }^{7-9}$ However, some characteristics of the social structure in a community may also have negative effects on social capital, social participation, and, in the next step of the causal pathway, health related behaviours such as tobacco smoking. Low tolerance towards minorities in a community with strong social networks has, for example, been named by Putnam as "the dark side of social capital". ${ }^{8}$ Another example of stable social structures which may weaken social capital and social participation and eventually affect health related behaviours in a detrimental way are work conditions, such as material or psychosocial conditions at work. Economic sources of progress in the material as well as the psychosocial work conditions may affect leisure time social capital, social participation, norms, attitudes and, ultimately, behaviours. This was recognised already in 19th century political philosophy-for example, by Karl Marx. ${ }^{10}$ More than 20 years ago, the demand-control model for the characterisation of psychosocial conditions at work was introduced by Robert Karasek and Töres Theorell. The basic and original model contains two dimensions or two latitudes. One dimension concerns the worker's control/decision latitude over his/her work situation in terms of creativity, repetitivity, as well as freedom and responsibility to decide what to do and when to do it. The other dimension concerns demands on the worker in terms of work pace, intensity, skills demanded to be able to do the work, and the possibility to keep up with the colleagues. Four different basic categories can be derived from this model. The psychosocial work conditions can be characterised as "relaxed" if control (decision latitude) is high and demands are low, "active" if control is high and demands are high, "passive" if control is low and demands are low, and "jobstrain" if control is low and demands are high. ${ }^{11}$ Jobstrain is positively associated with both increased cardiovascular disease and mortality. ${ }^{12-15}$ Even more interesting in this study, jobstrain (low control, high demands) has been shown to be positively associated with both smoking intensity ${ }^{16}{ }^{17}$ and smoking, ${ }^{16}$ although other studies have reported the association between jobstrain and smoking intensity to be more important than the association between jobstrain and smoking status. ${ }^{18}{ }^{19}$ It may be hypothesised that structural social conditions such as psychosocial conditions at work affect social capital and social participation. Persons with psychosocial work conditions characterised as "relaxed" or "active" with high control (decision latitude) over their work situation may, for psychological reasons for example, be expected to take more control and have higher decision latitudes over their social network activities during leisure time as well. Higher levels of social participation may thus be hypothesised in the "relaxed" and "active" categories compared to the "passive" and "jobstrain" categories as well 
as among the unemployed. In the next step in the chain of causality, low social participation/low social capital is, as already initially stated, well known to be positively associated with daily smoking. The causal chain from psychosocial work conditions to social participation, and in the next step from social participation to daily smoking, may thus be an example of how structural, economic, and production conditions affect social capital/social participation in order to affect a health related behaviour such as daily smoking in the next causal step.

The aim of this study is to investigate the two causal steps from psychosocial work conditions to social participation, and from social participation to daily smoking. In the final analysis, the relationship between social participation and daily smoking will be investigated within each of the four psychosocial conditions at work categories and within the unemployed category (which is included in this study because the unemployed are also a part of the potential work force).

\section{MATERIAL AND METHODS Population}

This empirical study is based on the population investigated by a postal questionnaire in Scania in southern Sweden from November 1999 to February 2000-the public health survey in Scania 2000-which is a cross sectional study of randomly chosen persons born from 1919 to 1981. Two reminder letters were also sent to the respondents. A total of 13715 individuals answered the questionnaire, which represents $59 \%$ of the net selection of respondents, but 111 lack information on sex and/or age. In the present study, 5180 individuals (2883 men and 2297 women) aged 18-64 years who reported their psychosocial conditions at work or were unemployed actively seeking employment (thus not reporting psychosocial work conditions but being part of the potential work force) are included. All individuals 65 years or older and all those not belonging to the work force or unemployed (housewives, sick leave pensioners, student, persons economically supported by the public welfare system, refugees) have been omitted. The random sample was weighted to some extent by age, sex, and geographic area in order to increase the statistical power in smaller administrative areas. In the statistical calculations of this study this has been corrected by a weighting variable, so that the representative prevalences (\%) for the entire Scania region are given. The differences in prevalences between the uncorrected and corrected data are very small.

\section{Definitions}

\section{Outcome}

The smoking item contains four alternatives: never smoked, stopped smoking, daily smoker, and intermittent (non-daily) smoker. The intermittent smoker, never smoked, and stopped smoking alternatives are merged into one category, which means that the smoking outcome variable is dichotomous in the final analysis: daily smokers and others.

\section{Independent variables}

Social participation-Social participation (during the past year) describes how actively the person takes part in the activities of formal and informal groups in society. Respondents were asked whether in the previous 12 months they had been involved in any of the following activities: study circle/course at workplace, other study circle/course, union meeting, meeting of other organisations, theatre/cinema, arts exhibition, church, sports event, letter to the editor of a newspaper/ journal, demonstration, night club/entertainment, large gathering of relatives, and private party. It is measured as an index consisting of 13 items and dichotomised. If three alternatives or less are indicated, the social participation of that individual is classified as low.

Work related psychosocial factors-Psychosocial work exposure is assessed by an instrument developed by Karasek and Theorell to measure psychological job demands and job decision (control) latitude. ${ }^{11}$ Individuals are given five questions assessing psychological job demands and six questions on control/decision latitude, and are instructed to respond on a scale from 1 to 4 . Overall scores for each category are calculated using the sum of weighted items. ${ }^{11}$ The scores for the two categories are dichotomised at the median into four groups: job situations characterised by high demands and low decision latitude (job strain), high demands and high decision latitude (active), low demands and low decision latitude (passive), and job situations with low demands and high decision latitude (relaxed).

Unemployed-The unemployed are also investigated in this study as a separate category, because they are a part of the potential work force and because they can be regarded as exposed to even higher levels of anxiety and, more important, insecurity than the jobstrain category.

Smoking intensity-Daily cigarette smoking is divided into $\geqslant 15$ cigarettes/day versus $<15$ cigarettes/day. A small minority (approximately 5\%) of the daily smokers are pipe, cigar, or cigarillo smokers. This small group has not been included in the analyses of the relation between psychosocial work conditions and smoking intensity $(\geqslant 15$ cigarettes $v$ $<15$ cigarettes/day).

Age-Age is divided into the age intervals 18-34, 35-44, 4554, and 55-64 years.

Sex-All analyses with the exception of the analyses in tables 2 and 5 are stratified by sex.

Country of origin-All persons born in countries other than Sweden are merged into a single category. Thus, the two categories used in the analysis are "Sweden" or "other".

Education-Education is divided by length of time spent in education into $\leqslant 9$ years, $10-12$ years, and $\geqslant 13$ years.

Economic stress-Economic stress is categorised by the answer to the question: "How many times during the past year did you not have money enough to afford the food or the clothes you and your family need?". The respondents are classified into four groups: (1) "Every month"; (2) "Approximately six months a year"; (3) "Very occasionally"; and (4) "Never".

\section{Statistics}

Prevalences (\%) stratified by sex of all the variables in the study are calculated (table 1). Prevalences (\%) and odds ratios with 95\% confidence intervals (OR, 95\% CI) of high smoking intensity (15 cigarettes/day or more) among daily cigarette smokers in the four psychosocial work conditions categories and among the unemployed are calculated adjusting for age, sex, country of origin, education, and economic stress (table 2). Prevalences (\%) of daily smoking are calculated by work related psychosocial conditions, social participation, age, country of origin, education and economic stress, both stratified by sex and total, with odds ratios and 95\% confidence intervals (table 3). Prevalences (\%) and crude, age adjusted, and multivariately adjusted odds ratios with $95 \%$ confidence intervals of low social participation are calculated for the work related psychosocial conditions categories (table 4). Crude, age adjusted, and multivariate analyses of daily smoking according to social participation (high $v$ low) are conducted within each of the four work related psychosocial conditions categories and the unemployed (table 5). The statistical analysis is performed using the SPSS software package. ${ }^{20}$ 
Table 1 Prevalences (\%) of daily smoking, demographic characteristics, socioeconomic characteristics, social participation, and psychosocial conditions at work and unemployment. Men $(n=2883)$, women $(n=2297)$, and total $(n=5180)$. The public health survey in Scania 2000

\begin{tabular}{|c|c|c|c|}
\hline & $\begin{array}{l}\text { Men } \\
(n=2883)\end{array}$ & $\begin{array}{l}\text { Women } \\
(n=2297)\end{array}$ & $\begin{array}{l}\text { Total } \\
(n=5180)\end{array}$ \\
\hline \multicolumn{4}{|l|}{ Smoking status } \\
\hline Daily smoker & 17.2 & 21.9 & 19.3 \\
\hline Intermittent smoker & 5.1 & 5.0 & 5.1 \\
\hline Stopped smoking & 27.9 & 24.3 & 26.4 \\
\hline Never smoked & 49.8 & 48.7 & 49.3 \\
\hline (Missing) & (20) & (19) & (39) \\
\hline \multicolumn{4}{|l|}{ Smoking intensity } \\
\hline Daily smoker, $>15$ cigarettes/day & 10.1 & 10.4 & 10.3 \\
\hline Daily smoker, $<15$ cigarettes /day & 5.6 & 11.1 & 8.0 \\
\hline Daily: pipe, cigar, cigarillo & 1.5 & 0.3 & 1.0 \\
\hline Intermittent smoker & 5.1 & 5.0 & 5.1 \\
\hline Non-smoker & 77.7 & 73.0 & 75.7 \\
\hline (Missing) & (20) & (19) & (39) \\
\hline \multicolumn{4}{|l|}{ Age (years) } \\
\hline $18-34$ & 30.4 & 28.4 & 29.5 \\
\hline $35-44$ & 25.5 & 24.2 & 24.9 \\
\hline $45-54$ & 26.2 & 29.7 & 27.7 \\
\hline $55-64$ & 17.9 & 17.8 & 17.8 \\
\hline (Missing) & (0) & (0) & (0) \\
\hline \multicolumn{4}{|l|}{ Country of origin } \\
\hline Sweden & 90.1 & 90.3 & 90.2 \\
\hline Other country & 9.9 & 9.7 & 9.8 \\
\hline (Missing) & (11) & (14) & (25) \\
\hline \multicolumn{4}{|l|}{ Education } \\
\hline$\geqslant 13$ years & 27.6 & 33.9 & 30.4 \\
\hline $10-12$ years & 50.2 & 46.1 & 48.4 \\
\hline$\leqslant 9$ years & 22.2 & 20.0 & 21.2 \\
\hline (Missing) & (33) & (40) & (73) \\
\hline \multicolumn{4}{|l|}{ Economic stress } \\
\hline Never & 72.6 & 69.6 & 71.3 \\
\hline Occasionally & 18.6 & 19.8 & 19.1 \\
\hline About six months a year & 4.3 & 4.7 & 4.5 \\
\hline Every month & 4.6 & 5.9 & 5.1 \\
\hline (Missing) & (19) & (18) & (37) \\
\hline \multicolumn{4}{|l|}{ Social participation } \\
\hline High & 76.0 & 79.5 & 77.6 \\
\hline Low & 24.0 & 20.5 & 22.4 \\
\hline (Missing) & (24) & (11) & (35) \\
\hline \multicolumn{4}{|l|}{ Psychosocial work conditions } \\
\hline Relaxed & 18.9 & 14.0 & 16.8 \\
\hline Active & 28.0 & 21.5 & 25.1 \\
\hline Passive & 22.8 & 25.8 & 24.1 \\
\hline Jobstrain & 18.2 & 23.5 & 20.5 \\
\hline Unemployed & 12.1 & 15.2 & 13.5 \\
\hline (Missing) & (0) & (0) & (0) \\
\hline Total & 100.0 & 100.0 & 100.0 \\
\hline
\end{tabular}

\section{RESULTS}

Table 1 shows that $17.2 \%$ of the men and $21.9 \%$ of the women are daily smokers. In contrast, the proportion of exsmokers is higher among men than among women, while the proportions of intermittent smokers and persons who have never smoked are very similar in both sexes. A majority of all male daily smokers are cigarette smokers who smoke 15 cigarettes or more per day, while female daily cigarette smokers are evenly distributed between smoking 15 cigarettes or more per day and less than 15 cigarettes per day. A small minority of daily smokers are pipe, cigar, or cigarillo smokers. The age group 18-34 years constitute $30.4 \%$ of the men and $28.4 \%$ of the women, while $26.2 \%$ of the men and $29.7 \%$ of the women belong to the age group $45-54$ years. A $9.9 \%$ proportion of all men and $9.7 \%$ of all women are born in other countries than Sweden. Almost a third of all participants (27.6\% among men and 33.9\% among women) have 13 years of education or more. The proportion of persons with economic stress every month, six months per year, or occasionally is $27.4 \%$ among men and $30.4 \%$ among women. Low social participation is reported from $24.0 \%$ of the men and $20.5 \%$ of the women. Psychosocial work conditions characterised as relaxed and active are more prevalent among men, while the categories passive and jobstrain as well as the unemployed are somewhat more common among women.

Table 2 shows that there are no significant differences when the psychosocial work conditions categories active, passive, and jobstrain as well as the unemployed are compared with the relaxed reference category. Adjustments for age, sex, country of origin, education, and economic stress do not alter these results. This non-significant result is the reason why smoking intensity is not included in the further analyses in tables 3, 4, and 5. The inclusion of economic stress in the model rather tends to reduce the non-significant differences even further.

Table 3 shows that the odds ratios of daily smoking are significantly higher in the jobstrain and unemployed groups compared to the relaxed reference group among both men and women. The odds ratios of daily smoking are also significantly higher in the low social participation compared to the high social participation group in both sexes. Daily smoking is also significantly more prevalent in the older age groups, among persons born in other countries than Sweden, among persons with low education, and among persons with economic stress than among the young (18-34 years), persons born in Sweden, persons with high education and persons without economic stress, respectively.

Table 4 shows that the odds ratios of low social participation are significantly higher in the passive, jobstrain, and unemployed categories compared to the relaxed reference category among both men and women. The odds ratios of having low social participation in the active category do not significantly differ from the relaxed reference category. The odds ratios of low social participation are particularly high among the unemployed. The odds ratios remain significant in the multivariate analyses adjusting for age,

Table 2 Prevalence $(\%)$ and odds ratios $(\mathrm{OR}, 95 \% \mathrm{Cl})$ of $\geqslant 15$ cigarettes per day smoking intensity among daily cigarette smokers in the psychosocial work conditions categories and among the unemployed. Men and women ( $n=937)$. The public health survey in Scania 2000

\begin{tabular}{|c|c|c|c|c|c|}
\hline & $\%$ & OR $(95 \% \mathrm{Cl})^{*}$ & OR $(95 \% \mathrm{Cl}) \dagger$ & OR $(95 \% \mathrm{Cl}) \ddagger$ & OR $(95 \% \mathrm{Cl}) \S$ \\
\hline Relaxed & 57.8 & 1.0 & 1.0 & 1.0 & 1.0 \\
\hline Active & 61.9 & $1.2(0.8$ to 1.9$)$ & $1.2(0.7$ to 1.9$)$ & $1.1(0.7$ to 1.8$)$ & 1.1 (0.7 to 1.7$)$ \\
\hline Passive & 48.1 & $0.7(0.4$ to 1.1$)$ & $0.7(0.4$ to 1.1$)$ & $0.7(0.4$ to 1.1$)$ & $0.6(0.4$ to 1.02$)$ \\
\hline Jobstrain & 53.1 & $0.8(0.5$ to 1.3$)$ & $0.9(0.6$ to 1.4$)$ & $0.8(0.5$ to 1.3$)$ & $0.8(0.5$ to 1.2$)$ \\
\hline Unemployed & 61.1 & $1.2(0.7$ to 1.8$)$ & $1.3(0.8$ to 2.0$)$ & $1.3(0.8$ to 2.0$)$ & $1.0(0.6$ to 1.7$)$ \\
\hline
\end{tabular}


Table 3 Prevalences (\%) and odds ratios (OR, 95\% Cl) of daily smoking according to psychosocial work conditions, social participation, age, country of origin, education and economic stress. Men $(n=2883)$ and women $(n=2297)$. The public health survey in Scania 2000

\begin{tabular}{|c|c|c|c|c|c|c|}
\hline & \multicolumn{2}{|c|}{ Men $(n=2883)$} & \multicolumn{2}{|c|}{ Women (n= 2297) } & \multicolumn{2}{|c|}{ Total $(5180)$} \\
\hline & $\%$ & OR $(95 \% \mathrm{CI})$ & $\%$ & OR $(95 \% \mathrm{CI})$ & $\%$ & OR $(95 \% \mathrm{Cl})$ \\
\hline \multicolumn{7}{|c|}{ Psychosocial work conditions } \\
\hline Relaxed & 14.3 & 1.0 & 18.2 & 1.0 & 15.6 & 1.0 \\
\hline Active & 14.0 & $1.0(0.7$ to 1.3$)$ & 16.2 & $0.9(0.6$ to 1.3$)$ & 14.7 & $0.9(0.7$ to 1.2$)$ \\
\hline Passive & 15.1 & $1.1(0.8$ to 1.8$)$ & 20.0 & $1.1(0.8$ to 1.6$)$ & 17.4 & $1.1(0.9$ to 1.4$)$ \\
\hline Jobstrain & 18.7 & $1.5(1.1$ to 1.9$)$ & 23.6 & $1.4(1.0$ to 2.0$)$ & 21.2 & 1.5 (1.2 to 1.8$)$ \\
\hline Unemployed & 31.1 & $2.7(2.0$ to 3.8$)$ & 34.4 & 2.4 (1.7 to 3.4$)$ & 32.8 & $2.6(2.1$ to 3.3$)$ \\
\hline (Missing) & $(18)$ & & (19) & & (37) & \\
\hline \multicolumn{7}{|l|}{ Social participation } \\
\hline High & 14.1 & 1.0 & 17.8 & 1.0 & 15.8 & 1.0 \\
\hline Low & 26.6 & 2.2 (1.8 to 2.7$)$ & 37.0 & 2.7 (2.2 to 3.4$)$ & 30.9 & 2.4 (2.1 to 2.8$)$ \\
\hline (Missing) & $(42)$ & & $(28)$ & & $(70)$ & \\
\hline \multicolumn{7}{|l|}{ Age (years) } \\
\hline $18-34$ & 12.0 & 1.0 & 18.5 & 1.0 & 14.7 & 1.0 \\
\hline $35-44$ & 19.2 & 1.7 (1.3 to 2.3 ) & 23.9 & $1.4(1.1$ to 1.8$)$ & 21.2 & 1.6 (1.3 to 1.9$)$ \\
\hline $45-54$ & 19.8 & 1.8 (1.4 to 2.4$)$ & 23.9 & $1.4(1.1$ to 1.8$)$ & 21.7 & $1.6(1.3$ to 1.9$)$ \\
\hline $55-64$ & 19.3 & 1.7 (1.3 to 2.4$)$ & 21.5 & $1.2(0.9$ to 1.6$)$ & 20.3 & 1.5 (1.2 to 1.8$)$ \\
\hline (Missing) & (20) & & (19) & & (39) & \\
\hline \multicolumn{7}{|l|}{ Country of origin } \\
\hline Sweden & 16.3 & 1.0 & 21.7 & 1.0 & 18.7 & 1.0 \\
\hline Other country & 24.0 & $1.6(1.2$ to 2.2$)$ & 25.0 & 1.2 (0.9 to 1.7$)$ & 24.6 & 1.4 (1.2 to 1.8$)$ \\
\hline (Missing) & (31) & & (34) & & $(65)$ & \\
\hline \multicolumn{7}{|l|}{ Education } \\
\hline 13- years & 10.9 & 1.0 & 12.4 & 1.0 & 11.6 & 1.0 \\
\hline 10-12 years & 15.6 & 1.5 (1.2 to 2.0$)$ & 25.4 & 2.4 (1.9 to 3.1$)$ & 19.7 & 1.9 (1.6 to 2.2$)$ \\
\hline-9 years & 28.3 & 3.2 (2.4 to 4.3 ) & 29.8 & $3.0(2.2$ to 4.0$)$ & 28.9 & 3.1 (2.5 to 3.8 ) \\
\hline (Missing) & (52) & & $(60)$ & & (112) & \\
\hline \multicolumn{7}{|l|}{ Economic stress } \\
\hline Never & 13.0 & 1.0 & 17.7 & 1.0 & 15.0 & 1.0 \\
\hline Occasionally & 22.5 & 2.0 (1.5 to 2.5$)$ & 26.6 & 1.7 (1.3 to 2.2 ) & 24.4 & 1.8 (1.5 to 2.2 ) \\
\hline About six months a year & 34.1 & 3.5 (2.4 to 5.2$)$ & 36.4 & 2.7 (1.8 to 4.1$)$ & 35.2 & 3.1 (2.3 to 4.1$)$ \\
\hline Every month & 39.2 & 4.3 (3.0 to 6.3 ) & 45.1 & 3.9 (2.7 to 5.6$)$ & 42.2 & $4.2(3.2$ to 5.4$)$ \\
\hline (Missing) & $(38)$ & & (37) & & (75) & \\
\hline
\end{tabular}

country of origin, education and economic stress. In particular, education tends to decrease the odds ratios of low social participation when included in the multivariate model.

Table 5 shows that the crude odds ratios of daily smoking are significantly higher among the study participants with low social participation compared to the reference category with high social participation within each of the psychosocial work conditions categories. The odds ratios of daily smoking are particularly high in the low social participation categories compared to the reference high social participation categories in the relaxed (OR 3.7, 95\% CI 2.4 to 5.8 ) and jobstrain (OR 2.2, 95\% CI 1.6 to 3.0 ) categories. Adjusting for age, sex, country of origin, education, and economic stress in the multivariate analyses decreases the odds ratios of daily smoking in the low social participation category within the relaxed, active, and passive psychosocial work conditions categories. In the active category the odds ratio even becomes non-significant. The odds ratios in the jobstrain and unemployed categories are only weakly affected by the adjustments in the multivariate analyses.

Table 4 Prevalences (\%) and crude and adjusted odds ratios (OR, 95\% CI) of low social participation according to psychosocial work conditions. Men $(n=2883)$ and women $(n=2297)$. The public health survey in Scania 2000

\begin{tabular}{|c|c|c|c|c|c|c|c|c|}
\hline & $\%$ & OR $(95 \% \mathrm{Cl})^{*}$ & OR $(95 \% \mathrm{Cl}) \dagger$ & OR $(95 \% \mathrm{Cl}) \ddagger$ & OR $(95 \% \mathrm{Cl}) \S$ & OR $(95 \% \mathrm{Cl})$ बा & $\mathrm{OR}^{* *}(95 \% \mathrm{Cl})$ & ORt† (95\% Cl) \\
\hline \multicolumn{9}{|l|}{ Men } \\
\hline Relaxed & 13.8 & 1.0 & 1.0 & 1.0 & 1.0 & 1.0 & 1.0 & 1.0 \\
\hline Active & 15.6 & $1.2(0.9$ to 1.6$)$ & $1.1(0.8$ to 1.5$)$ & $1.1(0.8$ to 1.6$)$ & $1.1(0.8$ to 1.5$)$ & $1.2(0.8$ to 1.6$)$ & $1.1(0.8$ to 1.5$)$ & $1.1(0.8$ to 1.5$)$ \\
\hline Passive & 27.9 & $2.4(1.8$ to 3.2$)$ & 2.5 (1.8 to 3.4$)$ & 2.4 (1.8 to 3.3$)$ & $1.8(1.3$ to 2.4$)$ & 2.4 (1.8 to 3.3$)$ & $1.8(1.3$ to 2.4$)$ & 1.8 (1.3 to 2.5$)$ \\
\hline Jobstrain & 27.5 & $2.4(1.7$ to 3.2$)$ & $2.5(1.8$ to 3.4$)$ & 2.4 (1.8 to 3.3$)$ & $1.9(1.4$ to 2.7$)$ & 2.3 (1.7 to 3.2$)$ & $1.9(1.4$ to 2.6$)$ & $2.0(1.4$ to 2.7$)$ \\
\hline Unemployed & 47.5 & $5.6(4.1$ to 7.8$)$ & $6.0(4.3$ to 8.3$)$ & 5.7 (4.1 to 7.9$)$ & 4.4 (3.1 to 6.2 ) & 4.6 (3.3 to 6.6$)$ & 3.7 (2.6 to 5.3$)$ & 3.6 (2.5 to 5.2$)$ \\
\hline \multicolumn{9}{|c|}{ (1) } \\
\hline Relaxed & 10.6 & 1.0 & 1.0 & 1.0 & 1.0 & 1.0 & 1.0 & 1.0 \\
\hline Active & 7.1 & $0.7(0.4$ to 1.1$)$ & $0.6(0.4$ to 1.03$)$ & $0.6(0.4$ to 1.04$)$ & $0.7(0.4$ to 1.1$)$ & $0.6(0.4$ to 1.0$)$ & $0.7(0.4$ to 1.1$)$ & 0.7 (0.4 to 1.2$)$ \\
\hline Passive & 20.8 & $2.2(1.5$ to 3.3$)$ & $2.2(1.4$ to 3.2$)$ & 2.1 (1.4 to 3.2$)$ & $1.6(1.0$ to 2.4$)$ & $2.0(1.4$ to 3.1$)$ & 1.5 (1.0 to 2.3$)$ & $1.7(1.1$ to 2.6$)$ \\
\hline Jobstrain & 24.0 & $2.6(1.8$ to 4.0$)$ & 2.5 (1.7 to 3.8$)$ & 2.5 (1.7 to 3.8$)$ & $1.9(1.3$ to 3.0$)$ & $2.4(1.6$ to 3.7$)$ & $1.9(1.2$ to 2.8$)$ & $2.0(1.3$ to 3.1$)$ \\
\hline Unemployed & 42.6 & $6.2(4.1$ to 9.4$)$ & 6.3 (4.1 to 9.5$)$ & 5.6 (3.7 to 8.5$)$ & 3.8 (2.4 to 5.8$)$ & 4.9 (3.2 to 7.6$)$ & $3.2(2.1$ to 5.1$)$ & 3.4 (2.1 to 5.3$)$ \\
\hline \multicolumn{9}{|c|}{$\begin{array}{l}\text { *Crude. } \\
\text { †Adjusted for age. } \\
\text { †Adjusted for age and country of origin. } \\
\text { §Adjusted for age, country of origin, and education. } \\
\text { †Adjusted for age, country of origin, and economic stress. } \\
\text { **Adjusted for age, country of origin, education, and economic stress. } \\
\text { ††Adjusted for age, country of origin, education, economic stress, and }\end{array}$} \\
\hline
\end{tabular}


Table 5 Prevalences (\%) and crude and adjusted odds ratios (OR, 95\% CI) of daily smoking according to social participation (Soc part) within each of the psychosocial work conditions categories. Men and women $(n=5180)$. The public health survey in Scania 2000

\begin{tabular}{|c|c|c|c|c|c|c|c|c|}
\hline & $\%$ & OR $(95 \% \mathrm{Cl})^{*}$ & OR $(95 \% \mathrm{Cl}) \dagger$ & OR $(95 \% \mathrm{Cl}) \ddagger$ & OR $(95 \% \mathrm{Cl}) \S$ & OR $(95 \% \mathrm{Cl}) \Phi$ & OR $(95 \% \mathrm{CI})^{\star *}$ & OR $(95 \% \mathrm{Cl})+t$ \\
\hline \multicolumn{9}{|l|}{ Relaxed } \\
\hline Soc part high & 12.8 & 1.0 & 1.0 & 1.0 & 1.0 & 1.0 & 1.0 & 1.0 \\
\hline $\begin{array}{l}\text { Soc part low } \\
\text { Active }\end{array}$ & 35.2 & 3.7 (2.4 to 5.8$)$ & $3.4(2.2$ to 5.4$)$ & 3.5 (2.2 to 5.6$)$ & 3.4 (2.2 to 5.5$)$ & 3.3 (2.1 to 5.3$)$ & 2.9 (1.8 to 4.7$)$ & 2.7 (1.7 to 4.5$)$ \\
\hline Soc part high & 13.6 & 1.0 & 1.0 & 1.0 & 1.0 & 1.0 & 1.0 & 1.0 \\
\hline $\begin{array}{l}\text { Soc part low } \\
\text { Passive }\end{array}$ & 22.5 & 1.8 (1.2 to 2.7$)$ & 1.7 (1.1 to 2.6$)$ & $1.9(1.3$ to 2.9$)$ & $1.9(1.3$ to 2.9$)$ & 1.6 (1.0 to 2.5$)$ & $1.4(0.9$ to 2.2$)$ & 1.2 (0.8 to 1.9$)$ \\
\hline Soc part high & 15.3 & 1.0 & 1.0 & 1.0 & 1.0 & 1.0 & 1.0 & 1.0 \\
\hline $\begin{array}{l}\text { Soc part low } \\
\text { Jobstrain }\end{array}$ & 23.9 & 1.7 (1.3 to 2.4$)$ & 1.6 (1.2 to 2.2$)$ & 1.7 (1.2 to 2.3 ) & $1.7(1.2$ to 2.4$)$ & $1.6(1.1$ to 2.2$)$ & $1.5(1.1$ to 2.1$)$ & 1.4 (1.0 to 2.0 ) \\
\hline Soc part high & 17.2 & 1.0 & 1.0 & 1.0 & 1.0 & 1.0 & 1.0 & 1.0 \\
\hline Soc part low & 31.1 & 2.2 (1.6 to 3.0$)$ & $2.2(1.6$ to 3.0$)$ & $2.2(1.6$ to 3.1$)$ & $2.3(1.6$ to 3.1$)$ & $2.2(1.6$ to 3.1$)$ & 2.1 (1.5 to 3.0$)$ & 2.1 (1.5 to 2.9 ) \\
\hline \multicolumn{9}{|l|}{ Unemployed } \\
\hline Soc part high & 26.3 & 1.0 & 1.0 & 1.0 & 1.0 & 1.0 & 1.0 & 1.0 \\
\hline Soc part low & 40.5 & $1.9(1.4$ to 2.6$)$ & 1.9 (1.4 to 2.7 ) & 1.9 (1.4 to 2.7$)$ & 2.0 (1.4 to 2.8$)$ & 1.9 (1.4 to 2.7$)$ & 1.7 (1.2 to 2.4$)$ & 1.7 (1.2 to 2.4$)$ \\
\hline $\begin{array}{l}\text { *Crude. } \\
\text { †Adjusted for } \\
\text { †Adjusted for } \\
\text { §Adjusted for } \\
\text { TAdjusted for } \\
{ }^{* *} \text { Adjusted for } \\
\text { ††Adjusted for }\end{array}$ & $\begin{array}{l}\text { age. } \\
\text { age ar } \\
\text { age, } s \\
\text { age, } s \\
\text { age, } \\
\text { r age, }\end{array}$ & $\begin{array}{l}\text { Ind sex. } \\
\text { sex, and country } \\
\text { sex, country of ori } \\
\text { sex, country of or } \\
\text { sex, country of o }\end{array}$ & $\begin{array}{l}\text { origin. } \\
\text { in, and economic } \\
\text { in, and education }\end{array}$ & tress. & & & & \\
\hline
\end{tabular}

\section{DISCUSSION}

This study shows that the jobstrain (high demands/low control) and unemployed categories have significantly higher odds ratios of daily smoking among both men and women compared to the relaxed (low demands/high control) reference category. The passive (low demands/low control), jobstrain, and unemployed categories are also significantly associated with low social participation. Low social participation is significantly and positively associated with daily smoking within each of the psychosocial work conditions and unemployed categories. Adjusting for age, country of origin, education, and economic stress in the multivariate analyses lowers the odds ratios of daily smoking in the low social participation category within the relaxed, active, and passive categories. In the active category the odds ratio even becomes non-significant after the adjustments. Particularly the unemployed category, but also to some extent the jobstrain category, has higher prevalences (\%) of daily smoking compared to the other categories. Psychosocial work conditions and unemployment may thus affect daily smoking both directly and, interestingly, through a pathway including social participation.

The participation rate is $59 \%$. The group born in countries other than Sweden is underrepresented in this investigation by approximately $5 \%$ compared to official register statistics for Scania (the proportion is approximately $10 \%$ in this investigation). This is partly due to an underrepresentation of persons born in countries other than Sweden in the study, and also partly due to the lower participation in the work force in this group. On the other hand, the prevalence of daily smoking corresponds very well with the smoking prevalences observed for the Scania region in other national and regional surveys. Furthermore, the distribution of the other sociodemographic variables in this study correspond very well with the general composition of the population of Scania in 2000 when compared with official statistical registers.

The validity and reliability of self reported items assessing smoking has consistently been shown to be good. ${ }^{21-24}$ Nondifferential misclassification seems to be a problem of less importance in this study, since non-differential misclassification tends to attenuate true differences, and the main results of this study show clear differences in daily smoking both according to psychosocial work conditions and social participation. The reliability and validity of the social participation index variable has previously been reported to be good..$^{25}$ The psychosocial work conditions categories derived from the Karasek-Theorell demand-control model are well established and validated and have been used since the beginning of the 1980s in many international studies. ${ }^{11}$

Age, sex, country of origin, education, and economic stress could be confounders of the associations between the psychosocial work conditions categories, unemployment, and social participation as well as between the psychosocial work conditions and unemployment categories, social participation, and daily smoking. Adjusting for these variables, however, only marginally affected the estimates. Within stratum confounding seems less plausible considering the fact that age is already divided into five age intervals.

The cross sectional design of this study makes it impossible to temporally draw inferences concerning causal pathways between psychosocial work conditions, social participation, and daily smoking. However, the causal pathway from psychosocial work conditions and unemployment to social participation outside of work to, in the next causal step, daily smoking seems to be the most plausible, because it is hard to imagine daily smoking affecting social participation and psychosocial work conditions, and social participation during leisure time affecting psychosocial work conditions.

The intermittent, non-daily smoker group constitutes a minor group with a prevalence of approximately $5 \%$ of the adult population. This group is included in the reference group which is compared with the daily smoker group in the analyses. Previous studies have shown that this group does not have an increased odds ratio of low social participation. ${ }^{27}$ Unpublished data from the 2000 questionnaire also demonstrate that there are only weak associations between intermittent smoking and the psychosocial work conditions variables.

Psychosocial conditions at work may affect the prevalence of daily smoking by a direct causal mechanism by which particularly the jobstrain situation, characterised by high demands and low control/low decision latitude, increases the prevalence of daily smoking by decreasing the chances of successful smoking cessation and by increasing the risk of previous non-smokers or intermittent, non-daily smokers of taking up daily smoking. This direct psychosocial mechanism 
has previously been suggested. ${ }^{16}$ However, this study has investigated an alternative, or rather complementary, indirect causal pathway between psychosocial work conditions and daily smoking. The first step in this indirect, two step causal pathway involves the impact of psychosocial work conditions on social participation. The second step concerns the effects of social participation on daily smoking. The second step in this causal pathway has already been thoroughly investigated and is well documented. $.^{3-6} 27-29$ This causal relationship between social participation and daily smoking may be theoretically explained by either the psychosocial stress theory, ${ }^{30}{ }^{31}$ the diffusion of innovations theory, ${ }^{32}$ or the social capital theory-that is, the norms and values inherent in social networks. ${ }^{83}$ The first step, from psychosocial work conditions to social participation, calls for a more detailed discussion concerning the impact of the psychosocial demand-control/decision latitude categories on general social participation. The low demand and high decision latitude/ high control category-the relaxed category-is theoretically the ideal one, which is the major reason why this category has been used as the reference category in the statistical analyses in this study. The low demand and low decision latitude/low control category-the passive one-may be associated with loss of skills and to some extent psychological atrophy. ${ }^{11}$

Such processes of loss of skills and psychological atrophy may also affect both the inclination of the individual to initiate social participation at work or during leisure time, as well as the inclination of the individual to maintain the social networks and the social participation already present. This notion is supported by the data of this study, which shows that the prevalence of low social participation in the passive category was significantly higher than the prevalence of low social participation in the relaxed reference category $(27.9 \% \mathrm{v}$ $13.8 \%$ among men, and $20.8 \% v 10.6 \%$ among women). High decision latitude/high control and high demands in the active category most plausibly stimulates active learning. Active learning in the active situation may stimulate feelings of mastery and control, even in unofficial social networks at work and in other social networks during leisure time. ${ }^{34}$ This notion is also supported in this study. The prevalence of low social participation in the active category (15.6\% among men and $7.1 \%$ among women) does not significantly differ from the corresponding prevalence in the relaxed reference category.

Finally, the accumulated psychosocial strain in the jobstrain situation - that is, low decision latitude/low control and high demands-may lead to accumulated anxiety which inhibits active learning and social contacts. ${ }^{34}$ This notion is also supported by the statistical findings of this study. The prevalence of low social participation was significantly higher in the jobstrain category $(27.5 \%$ among men and $24.0 \%$ among women) compared to the relaxed reference category. The passivity and lack of possibilities to acquire new skills or uphold already acquired skills in the unemployed category, a group without any psychosocial work conditions but with probably even more elevated anxiety, most plausibly leads to low social participation, a notion also strongly supported by the statistical results of this study.

The two step psychosocial work conditions-social participation and daily smoking causal model is also supported in the empirical results by the fact that there are strong significant and positive associations between low social participation and daily smoking within each of the psychosocial work conditions categories. The most crucial factor thus seems to be the prevalence of low social participation within each of the psychosocial work conditions categories, even if the prevalences of daily smoking are also somewhat higher for both low and high social participation within the jobstrain

\section{What this paper adds}

A causal relation between adverse psychosocial conditions at work, especially "jobstrain" (high demands and low control), and daily smoking has previously been suggested. Such a direct causal pathway may be explained by a psychosocial mechanism by which the high anxiety among workers experiencing jobstrain decreases the inclination to stop smoking and maybe also increases the inclination to take up smoking. However, an indirect causal pathway by which psychosocial conditions at work may affect daily smoking is by affecting social participation in an intermediary step. It is well known that daily smoking is significantly associated with low social participation. Psychosocial conditions at work may affect social participation. The accumulated psychosocial strain in the jobstrain situation may, for example, lead to accumulated anxiety which inhibits active learning and social contacts, while active learning in the active (high demands/high control) category may stimulate feelings of mastery and control, even in social networks outside work. The statistical analyses of this study support this notion of an indirect causal pathway between psychosocial work conditions and daily smoking mediated by social participation.

category, and much higher for both high and low social participation within the unemployed. The somewhat lower prevalence of daily smoking in the passive category compared to the jobstrain category, in spite of the similar prevalences of low social participation, may also be explained by the weaker positive statistical association between low social participation and daily smoking within the passive category compared to the jobstrain category.

The idea of a two step causal mechanism between psychosocial work conditions and daily smoking with social participation as an intermediary step is also supported by the fact that the law concerning work environment in Sweden safeguards a smoke-free work environment. ${ }^{35}$ This fact makes the notion that psychosocial work conditions affect daily smoking by affecting social participation outside work a highly plausible causal mechanism.

The non-significant result of the analyses in table 2 of the association between psychosocial work conditions and smoking intensity among daily cigarette smokers is contrary to the finding in some other studies where such associations have been reported to be more important than the relation between psychosocial work conditions and daily smoking per se. $^{18} 19$

The results of this study have important implications for public health policy. Stable social conditions such as stable social structures, stable social networks, and low migration rates are often stated as the most beneficial preconditions for a society or community characterised by high social capital. However, some stable social conditions such as psychosocial work conditions may also be obstacles to the formation of social capital, and thus also obstacles to the formation and maintenance of benevolent health related behaviours such as non-smoking. Actions to stimulate social networks and empowerment in order to promote better health related behaviours may thus be hampered by social structures in or outside work life which strongly determine social networks and social participation. Political action to change these structures may be needed. This critique against the proponents of social capital and social networks as the answer to social and economic differences in health has already been formulated in more general terms. ${ }^{36}{ }^{37}$ The findings of this study do not out rule the possibility of effectively stimulating 
good health related behaviour by promoting social networks, but they point to the fact that underlying structural conditions may also be important.

\section{Conclusion}

The positive association between low social capital/low social participation and daily smoking is well known. However, both social participation and daily smoking are associated with psychosocial work conditions and unemployment. Psychosocial work conditions and unemployment thus may affect daily smoking both directly and through a pathway including social participation.

\section{ACKNOWLEDGEMENTS}

This study was supported by grants from the Medical Faculty, Lund University, Sweden. The author wish to thank Professor Robert Karasek for interesting and fruitful discussions on several occasions during the summer of 1999.

\section{REFERENCES}

1 Kawachi I, Kennedy BP, Glass R. Social capital and self-rated health: a contextual analysis. Am J Public Health 1999;89:1187-93.

2 Kawachi I, Kennedy BP, Wilkinson RG. Crime: social disorganization and relative deprivation. Soc Sci Med 1999:48:719-31.

3 Lindström M, Hansson BS, Östergren P-O, et al. Socioeconomic differences in smoking cessation: the role of social participation. Scand J Public Health 2000;28:200-8.

4 Lindström M. Social capital and the miniaturization of community among daily and intermittent smokers: a population-based study. Prev Med 2003;36: 177-84

5 Lindström M, Isacsson S-O. Smoking cessation among daily smokers, aged 45-69 years: a longitudinal study in Malmö, Sweden. Addiction 2002:97:205-15

6 Lindström M, Isacsson S-O, Elmståhl S. Impact of different aspects of social participation and social capital on smoking cessation among daily smokers: a longitudinal study. Tobacco Control 2003;12:274-81

7 Putnam RD. Bowling alone. America's declining social capital. Journal of Democracy 1995;6:65-78.

8 Putnam RD. Bowling alone. The collapse and revival of American community. New York: Simon and Schuster, 2000.

9 Kawachi I, Berkman L. Social cohesion, social capital, and health. In: Berkman L, Kawachi I, eds. Social epidemiology. Oxford, New York: Oxford University Press, 2000.

10 Tannenbaum D, Schultz D. Inventors of ideas. An introduction to western political philosophy, 2nd ed. Australia, Canada, Mexico, Singapore, Spain, UK, USA: Thomson Wadsworth, 2004.

11 Karasek R, Theorell T. Healthy work. Stress, productivity and the reconstruction of working life. New York: Basic Books, 1990.

12 Haynes SG, Feinleib M, Kannel WB. The relationship of psychosocial factors to coronary heart disease in the Framingham study. Am J Epidemiol 1980;1 11:37-58.

13 Karasek R, Baker D, Marxer F, et al. Job decision latitude, job demands, and cardiovascular disease: a prospective study of Swedish men. Am J Public Health 1981;71:694-705.

14 Karasek R, Theorell T, Schwartz J, et al. Job, psychological factors and coronary heart disease. Adv Cardiol 1982;29:62-7.
15 Siegrist J, Peter R, Junge A, et al. Low status control, high effort at work and ischemic heart disease: prospective evidence from blue-collar men. Soc Sci Med 1990;31:1127-34.

16 Hellerstedt WL, Jeffery RW. The association of job strain and health behaviours in men and women. Int J Epidemiol 1997;26:575-83.

17 Suadicani P, Hein HO, Gyntelberg. Are social inequalities associated with the risk of ischaemic heart disease a result of psychosocial working conditions? Atherosclerosis 1993;101:165-75.

18 Greenlund KJ, Liu K, Knox S, et al. Psychosocial work characteristics and cardiovascular disease risk factors in young adults: the CARDIA study. Coronary artery risk disease in young adults. Soc Sci Med 1995;41:717-23.

19 Niedhammer I, Goldberg M, Leclerc A, et al. Psychosocial work environment and cardiovascular risk factors in an occupational cohort in France. J Epidemiol Community Health 1998;52:93-100.

20 Norusis MJ. SPSS for windows. Advanced statistics, Release 10.0. Chicago: SPSS Inc, 1999.

21 Tate JC, Pomerleau CS, Pomerleau OF. Pharmacological and nonpharmacological smoking motives: a replication and extension. Addiction 1994;89:321-30

22 Verkerk PH, Buitendijk SE, Verloove-Vanhorick SP. Differential misclassification of alcohol and cigarette consumption by pregnancy outcome. Int J Epidemiol 1994;23:1218-25.

23 Steffensen FH, Lauritzen T, Sörensen HT. Validity of self-reported smoking habits. Scand J Prim Health Care 1995:13:236-7.

24 Wells AJ, English PB, Posner SF, et al. Misclassification rates for current smokers misclassified as nonsmokers. Am J Public Health 1998;88:1503-9.

25 Hanson BS, Östergren P-O, Elmståhl S, et al. Reliability and validity assessements of measures of social network, social support and control- results from the Malmö shoulder and neck study. Scand J Soc Med 1997;25:249-57.

26 National Central Bureau of Statistics. Living conditions. Isolation and togetherness- An outlook on social participation 1976, Report no.18. Stockholm: The National Central Bureau of Statistics, 1980.

27 Lindström M, Östergren P-O. Intermittent and daily smokers: two different socioeconomic patterns, and diverging influence of social participation and social capital. Tobacco Control 2001;10:258-66.

28 Lindström M. Social participation, social capital and socioeconomic differences in health-related behaviours. Malmö: Department of Community Medicine, Lund Univesity, 2000 (thesis)).

29 Lindström $M$, Isacsson S-O. Long term and transitional intermittent smokers: a longitudinal study. Tobacco Control 2002;11:61-7.

30 Selye $\mathbf{H}$. The general adaptation syndrome and the disease of adaptation. J Clin Endocrinol 1946:6:112-230.

31 Syme L. Control and health: a personal perspective. In: Steptoe A, Appels A, eds. Stress, personal control and health. Chichester: John Wiley and Sons, 1989.

32 Rogers E. Diffusion of innovations. New York: The Free Press, 1983.

33 Putnam RD. Making democracy work. Civic traditions in modern Italy. Princeton: Princeton University Press, 1993.

34 Theorell T. Working conditions and health. In: Berkman L, Kawachi I, eds. Social epidemiology. Oxford: Oxford University Press, 2000.

35 The National Institute of Public Health. Andras rök och din hälsa. Forskning om passiv rökning. (The smoke of others and your health. Research on passive smoking.). Stockholm: Folkhälsoinstitutet (The National Institute of Public Health), 16, 2001

36 Muntaner C, Lynch J. Income inequality, social cohesion, and class relations: a critique of Wilkinson's neo-durkheimian research program. Int $J$ Health Services 1999;29:59-81.

37 Muntaner C, Lynch J, Davey Smith G. Social capital, disorganised communities, and the third way: understanding the retreat from structural inequalities in epidemiology and public health. Int $J$ Health Services $2001 ; 31: 213-37$ 